\title{
Firearm-related injuries among Canadian children and youth from 2006 to 2013: A CHIRPP study
}

\author{
Catherine M.J. Cox, MPH, MD*; Samuel A. Stewart, $\mathrm{PhD}^{\dagger}$; Katrina F. Hurley, MD, MHI ${ }^{\ddagger \S}$
}

\begin{abstract}
CLINICIAN'S CAPSULE
What is known about the topic?

Injuries from non-powder firearms are common and potentially life-altering. The Canadian Pediatric Society urges stricter controls on non-powder guns.

What did this study ask?

What are the Canadian contextual trends in paediatric firearm injuries?

What did this study find?

In this study, the rate of paediatric firearm injuries was stable from 2006 to 2013. Eye injuries inflicted by nonpowder firearms were most common. Most firearm injuries occurred through recreation and sport.

Why does this study matter to clinicians?

Parents who receive physician counselling about firearm safety report change in practice. This study highlights settings/individuals that may be appropriate targets for intervention.
\end{abstract}

\section{ABSTRACT}

Objective: The purpose of this study was to describe Canadian contextual trends in pediatric firearm injuries and death from powder and non-powder firearms.

Methods: This is a registry study of firearm-related injuries captured by the Canadian Hospitals Injury and Reporting Prevention Program (CHIRPP) for children ages 0 to 18 years presenting to participating CHIRPP emergency departments (EDs) from 2006 to 2013. Data included age, sex, year, setting, circumstance, and disposition for each case.

Results: The CHIRPP dataset included 325 non-powder firearm injuries and 80 powder gun injuries. The rate of firearm injuries remained stable from 2006 to 2013 (44 per 100,000 ED visits). Forty-five patients required hospital admission and 2 died in the ED; 8 of 9 intentional self-harm injuries were inflicted with a powder gun. Most injuries occurred unintentionally from non-powder firearms $(n=298,71 \%)$ in the context of recreation $(n=179)$ and sport $(n=48)$. Eyes were the most commonly injured body part $(n=150), 98 \%$ of which resulted from a non-powder firearm. Forty-three percent $(n=141)$ of nonpowder firearm injuries required treatment or admission.

Conclusions: Eye injuries inflicted by non-powder firearms are a prevalent category of firearm-related injury. Most occurred through recreation and sport, highlighting a potential focus for primary prevention.

\section{RÉSUMÉ}

Objectif: Létude visait à décrire les tendances relatives aux blessures et aux morts causées par les armes à feu à poudre et non à poudre, chez les enfants et les jeunes, dans le contexte canadien.

Méthode: Il śagit d'une étude fondée sur le registre SCHIRPT (Système canadien hospitalier d'information et de recherche en prévention des traumatismes) et menée chez des enfants âgés de 0 à 18 ans, qui ont subi des blessures causées par des armes à feu et qui ont été traités dans ĺun des services des urgences (SU) participant au SCHIRPT, de 2006 à 2013. Ont été recueillies, dans chacun des cas, des données sur lâge, le sexe, ĺannée, le lieu, les circonstances et lissue.

Résultats: La base de données du SCHIRPT comptait 325 cas de blessures causées par des armes à feu non à poudre et 80 cas de blessures causées par des armes à feu à poudre. Le taux de blessure par arme à feu est resté stable, de 2006 à 2013 (44 cas pour 100,000 consultations au SU). Sur le total, 45 patients ont dû être hospitalisés et 2 sont morts au SU. Sur 9 blessures volontaires, 8 ont été infligées par des armes à feu à poudre. Toutefois, la plupart des blessures ( $n=298 ; 71 \%$ ) étaient involontaires et causées par des armes à feu non à poudre, et elles sont survenues dans un contexte de loisirs $(n=179)$ ou de sport $(n=48)$. La partie du corps la plus touchée était les yeux ( $n=150$ ), et $98 \%$ des blessures oculaires résultaient de coups tirés par des armes à feu non à poudre. Dans $43 \%$ des cas $(n=141)$, les blessures causées par des armes à feu non à poudre ont nécessité des traitements ou Íhospitalisation.

Conclusions: Les blessures aux yeux causées par les armes à feu non à poudre forment ĺune des catégories les plus importantes du tableau. La plupart des accidents sont survenus dans un contexte de loisir ou de sport, ce

From the *Department of Family Medicine; †Medical Informatics, Department of Community Health \& Epidemiology; $¥ D$ Department of Emergency Medicine, Dalhousie University, Halifax, NS; and §IWK Health Centre, Emergency Department, Halifax, NS.

Correspondence to: Dr. Katrina Hurley, Department of Emergency Medicine, IWK Health Centre, 5850/5980 University Avenue, PO Box 9700 , Halifax, NS B3K 6R8, Canada; Email: kfhurley@dal.ca 
qui justifierait ĺélaboration d'interventions en prévention primaire.
Keywords: epidemiology, eye injury, injury prevention, non-powder firearm, pediatric

\section{INTRODUCTION}

Nearly one Ontario youth is injured each day by a firearm. ${ }^{1}$ The Canadian Pediatric Society (CPS) has urged stricter controls on non-powder guns powerful enough to penetrate tissue. ${ }^{2}$ Injuries from non-powder firearms (guns that do not use gun powder such as BB, pellet, or airguns) are usually non-lethal but may be life-altering. ${ }^{3}$ In the United States, airgun injuries accounted for $10 \%$ of sport-related eye injuries, $26.4 \%$ of which caused impaired vision. ${ }^{4}$

The Canadian Hospitals Injury and Reporting Prevention Program (CHIRPP) is a richly detailed national database of "pre-event" injury data. Data come from questionnaires completed by patients and staff in 11 pediatric emergency departments (EDs) and 6 general EDs. Coders abstract data elements from patients' narratives. ${ }^{5}$ We aim to describe contextual trends in firearm injuries in Canadian children.

\section{METHODS}

This is a registry study of ED visits for children ages 0 to 18 years with firearm-related injuries captured by CHIRPP. Firearm injury cases from 2006 to 2016 were extracted by the CHIRPP data and research manager (Ottawa) through a database query for records with any of the following codes: "Gas, air or spring-operated guns, INCL BB guns, pellet guns"; "Guns, firearms and rifles, NEC"; "Gunpowder, ammunition and explosives, INCL bombs"; "BBs and pellets"; "Firearms, INCL airguns, BB guns, rifles, handguns and flare guns"; and "Intentional self-harm by rifle, shotgun, handgun, or other firearm." The query also captured records containing any of these keywords: $B B$ (and punctuation variations), pellet, gun, shot, shoot, scope, rifle, firearm, firearm, pistol(e), revolver, bullet, trigger, airsoft, air soft, coup de feu, arme a feu, arme à feu, fusil, and carabine. The total number of encounters per year for all injuries was determined to provide denominators for gun injury rates per 100,000 ED visits.

Exclusion criteria were age $>18$ years, lacking sufficient descriptive information to determine whether the injury resulted from firearm use, and injury description that was not consistent with firearm use. The patient narratives for each case in the dataset were hand searched by two authors to find cases that should be excluded. Variables extracted for comparison included age, sex, year of injury, nature of injury, context of injury, type of firearm, and injured body part. The

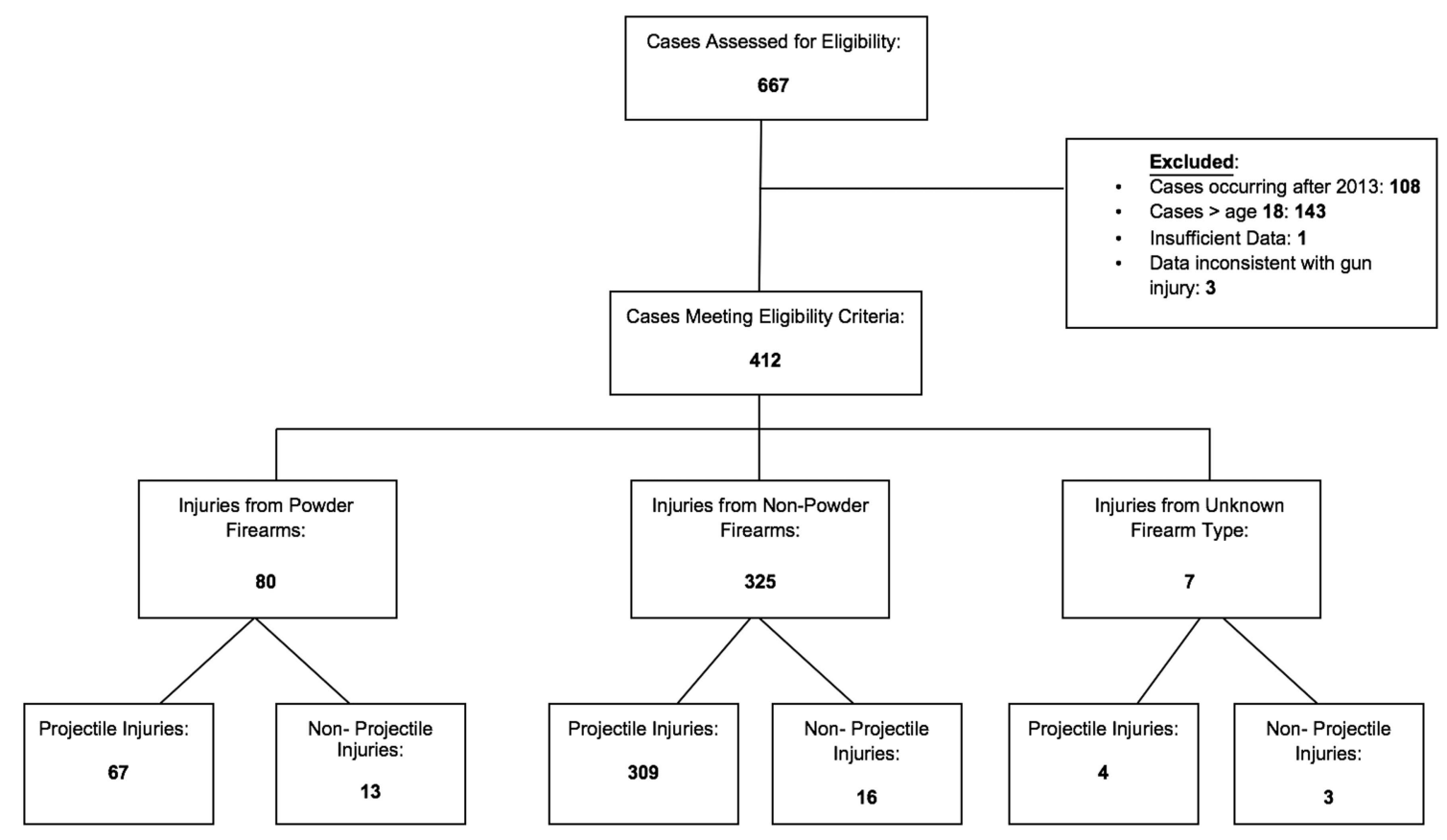

Figure 1. Total number of CHIRPP cases for study eligibility by firearm type and mechanism of injury. 


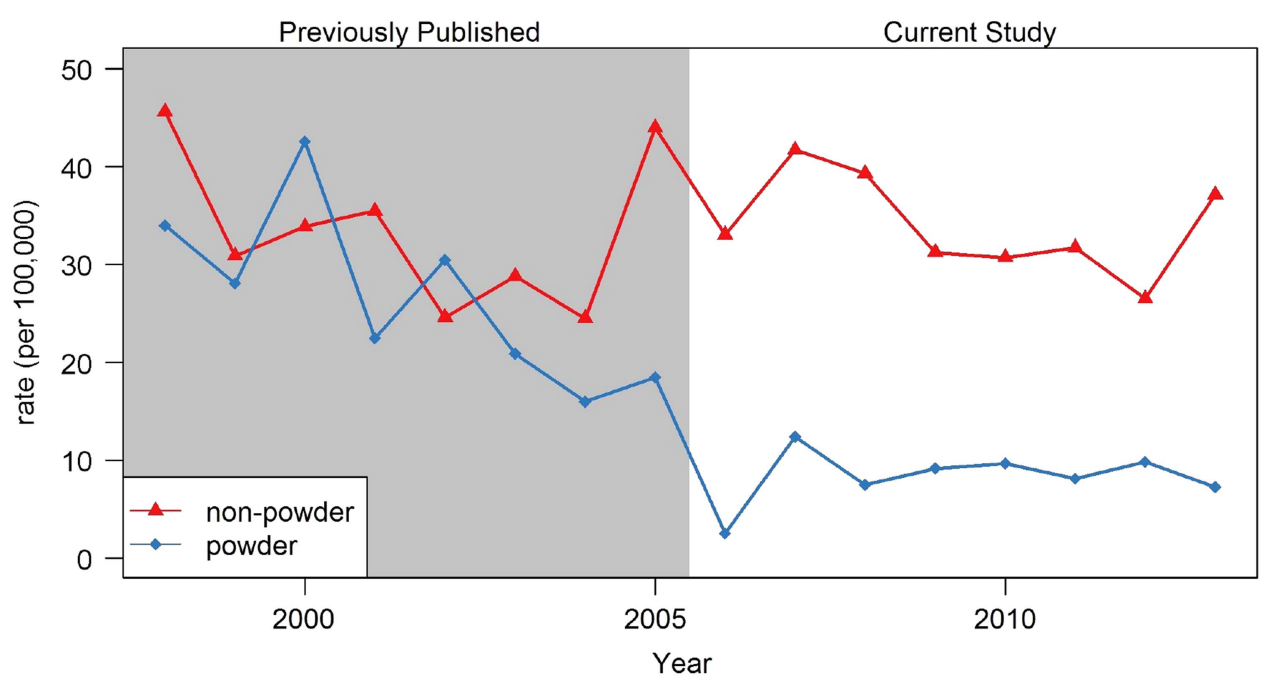

Figure 2. Rate of firearm injuries per 100,000 CHIRPP ED visits, by firearm type.

\begin{tabular}{|c|c|c|c|}
\hline & Powder firearm & Non-powder firearm & Unknown \\
\hline & \# cases $(\%)$ & \# cases (\%) & $\#$ cases $(\%)$ \\
\hline \multicolumn{4}{|l|}{ Gender } \\
\hline Male & $65(18)$ & $289(81)$ & $5(1)$ \\
\hline Female & $15(28)$ & $36(68)$ & $2(4)$ \\
\hline \multicolumn{4}{|l|}{ Age group } \\
\hline$<4$ & $2(29)$ & $5(71)$ & $0(0)$ \\
\hline 5 to 9 & $9(16)$ & $46(84)$ & $0(0)$ \\
\hline 10 to 14 & $36(16)$ & $183(82)$ & $3(1)$ \\
\hline 15 to 18 & $32(26)$ & $89(71)$ & $4(3)$ \\
\hline \multicolumn{4}{|l|}{ Context } \\
\hline Active & $8(28)$ & $20(69)$ & $1(3)$ \\
\hline Bystander & $1(17)$ & $5(83)$ & $0(0)$ \\
\hline Fight & $9(69)$ & $4(31)$ & $0(0)$ \\
\hline Housework & $5(19)$ & $19(73)$ & $2(8)$ \\
\hline Intentional & $9(100)$ & $0(0)$ & $0(0)$ \\
\hline Recreation & $15(8)$ & $163(91)$ & $1(0.6)$ \\
\hline Sport & $19(40)$ & $27(56)$ & $2(4)$ \\
\hline Work & $1(33)$ & $2(67)$ & $0(0)$ \\
\hline Missing & $13(13)$ & $85(86)$ & $1(1)$ \\
\hline
\end{tabular}

dataset was truncated after 2013 due to missing data to allow for comparable calculated firearm injury rates. All analyses were done using $\mathrm{R}$ version 3.2.2.

\section{RESULTS}

The dataset provided by CHIRPP included 667 cases, and 255 cases were excluded: cases occurring after 2013 $(n=108)$, age $>18$ years $(n=143)$, insufficient data to verify firearm injury $(\mathrm{n}=1)$, and description not consistent

\begin{tabular}{|c|c|c|c|}
\hline & Powder firearm & Non-powder firearm & Unknown \\
\hline & \# cases $(\%)$ & \# cases $(\%)$ & \# cases $(\%)$ \\
\hline Admitted & $34(76)$ & $11(24)$ & $0(0)$ \\
\hline Advice & $1(5)$ & 19 (95) & $0(0)$ \\
\hline Died & $2(100)$ & $0(0)$ & $0(0)$ \\
\hline Left & 1 (33) & $2(67)$ & $0(0)$ \\
\hline Observed & $1(4)$ & $26(96)$ & $0(0)$ \\
\hline Treated & $16(11)$ & $130(87)$ & $3(2)$ \\
\hline Missing & $25(15)$ & $137(83)$ & $4(2)$ \\
\hline
\end{tabular}

with firearm injury $(\mathrm{n}=3)$ (Figure 1$)$. We analysed 412 firearm injuries: 325 injuries by non-powder firearms, 80 injuries by powder guns, and 7 injuries by an unknown firearm. Most injuries resulted from a projectile: $95 \%$ $(n=309)$ of non-powder firearm injuries and $84 \%$ $(n=67)$ of powder gun injuries (Figure 1).

The number of firearm-related injuries per 100,000 ED visits remained stable from 2006 to 2013 overall (Figure 2). The age groups in which injuries occurred most often were 10 to 14 years and 15 to 18 years with a male predominance $(80.5 \%, \mathrm{n}=359)$. Most injuries occurred unintentionally by non-powder firearms in the context of recreation (disorganized physical activity; $\mathrm{n}=179$ ) and sport (organized physical activity; $\mathrm{n}=48$ ). Eight of nine instances of intentional self-harm were from a powder gun (Table 1).

Overall, 45 individuals required admission to the hospital, and 2 died in the ED. Forty-three percent of injuries from non-powder firearms required treatment 
$(\mathrm{n}=130)$ or admission $(\mathrm{n}=11)$ (Table 2). Eye injuries were the most common injury $(n=150)$ with $98 \%$ from nonpowder firearms. The use of protective eyewear was noted in 12 instances. Overall, the "external cause of injury" was "a child or adult other than the victim" in 149 cases.

\section{DISCUSSION}

Non-powder firearm injuries continue to raise concern with reports of vision loss and even death. ${ }^{3,6,7}$ Our study demonstrates that firearm injuries have remained stable from 2006 to 2013, despite the cancellation of Canada's long gun registry and an increase in airgun sales and related injuries in the United States. ${ }^{3}$

Eye injuries from non-powder firearms were the most common in our dataset. In the United States, these injuries are the leading cause of pediatric eye injuries requiring admission. ${ }^{3}$ There are at least 56 published cases of vision loss after a non-powder firearm injury. ${ }^{3}$ There is little to indicate that protective eyewear would prevent vision loss in these cases, but given that many of the victims are persons other than the "shooter," use of protective eyewear for the shooter may not help. ${ }^{4}$

Parents who receive physician counselling about firearm safety report higher rates of handgun removal and safer storage. ${ }^{8}$ More research is needed to determine whether physician counselling is similarly effective for non-powder firearms, which are largely viewed as toys. While the context of firearm-related injury in the United States differs from Canada, studies comparing pediatric injury according to the stringency of state firearm laws suggest that legislation matters. ${ }^{9,10}$ Classifying higher velocity non-powder firearms under Canada's Firearms Act and bringing lower velocity non-powder firearms under the Canada Consumer Product Safety Act, ${ }^{6}$ as advocated by the CPS, may diminish these injuries.

\section{LIMITATIONS}

Data extraction was performed by a single data extractor and reviewed by two authors to ensure that included cases were appropriate. We were not able to assess cases that may have been erroneously excluded. Most CHIRPP data come from hospitals in cities so injuries of older teenagers, First Nation and Inuit people, and inhabitants of rural and remote areas are underrepresented. CHIRPP also underrepresents fatal injuries as it does not capture prehospital deaths. ${ }^{11}$ Injuries in patients who refused to complete the data collection form are also missed. ${ }^{12}$

\section{CONCLUSION}

Overall, the rate of firearm-related injuries in children and youth presenting to participating CHIRPP EDs was stable from 2006 to 2013. Eyes were most commonly injured, and these were most often caused by non-powder firearms. Most injuries occurred during sport and recreation and were inflicted by someone other than the victim, highlighting settings and individuals that may be appropriate targets for intervention.

Acknowledgements: Data used in this publication are from the Canadian Hospitals Injury Reporting and Prevention Program (CHIRPP) and are used with the permission of the Public Health Agency of Canada (PHAC). Thanks to Jennifer Crain of PHAC for creating the dataset. The analyses and interpretations presented in this work do not necessarily reflect the opinions of the federal government.

Competing interests: None declared.

\section{REFERENCES}

1. Saunders NR, Lee H, Machperson A, et al. Risk of firearm injuries among children and youth of immigrant families. CMA7 2017;189(12):E452-8.

2. Austin K, Lane M. Canadian pediatrics position statement. The prevention of firearm injuries in Canadian youth. The Canadian Pediatric Society Adolescent Health Committee. Available at: https://www.cps.ca/en/documents/position/theprevention-of-firearm-injuries-in-canadian-youth (accessed 22 August 2017).

3. Lee R, Fredrick D. Pediatric eye injuries due to non-powder guns in the United States, 2002-2012. 7 AAPOS 2015;19(2): 163-8.e1, doi:10.1016/j.jaapos.2015.01.010.

4. Haring RS, Sheffield ID, Canner JK, Schneider EB. Epidemiology of sports-related eye injuries in the United States. FAMA Ophthalmol 2016;134(12):1382-90, doi:10.1001/jamaophthalmol.2016.4253.

5. Crain J, McFaull S, Thompson W, Skinner R. Status report - the Canadian Hospitals Injury Reporting and Prevention Program: a dynamic and innovative injury surveillance system. Health Promot Chronic Dis Prev Can 2016;36(6):112-7.

6. Veenstra M, Prasad J, Schaewe H, et al. Non-powder firearms cause significant pediatric injuries. I Trauma Acute Care Surg 2015;78(6):1138-42, doi:10.1097/ TA.0000000000000642.

7. O’Neill PJ, Lumpkin MF, Clapp B, et al. Significant pediatric morbidity and mortality from intracranial ballistic injuries caused by non-powder gunshot wounds. A case series. Pediatr Neurosurg 2009;45(3):205-9, doi:10.1159/ 000222671.

8. Garbutt JM, Bobenhouse N, Dodd S, et al. What are parents willing to discuss with their pediatrician about 
Cox et al

firearm safety? A parental survey. 7 Pediatr 2016;179:166-71, doi:10.1016/j.jpeds.2016.08.019.

9. Safavi A, Rhee P, Pandit V, et al. Children are safer in states with strict firearm laws: a national inpatient sample study. 7 Trauma Acute Care Surg 2014;76(1):146-50; discussion 150-1, doi:10.1097/TA.0b013e3182ab10fb.

10. Tashiro J, Lane RS, Blass LW, et al. The effect of gun control laws on hospital admissions for children in the
United States. 7 Trauma Acute Care Surg 2016;81(4 Suppl 1): S54-60, doi:10.1097/TA.0000000000001177.

11. Herbert M, Mackenzie SG. Injury surveillance in paediatric hospitals: the Canadian experience. Paediatr Child Health 2004;9(5):306-8.

12. Mackenzie SG, Pless IB. CHIRPP: Canada's principal injury surveillance program. Canadian Hospitals Injury Reporting and Prevention Program. Inj Prev 1999;5:208-13. 